\title{
Evaluation of insulin-like growth factor-1, total ghrelin, and insulin resistance in nutritionally stunted Egyptian children
}

\author{
Shimaa M. Abdou'; Noha A. El-Boghdady ${ }^{1}$; Awatif M. Abd El-Maksoud ${ }^{3}$; Sahar \\ A. Khairy'; Maha M. El-Sawalhi, ${ }^{1,4}$
}

Original Article

\author{
${ }^{I}$ Faculty of Pharmacy, Department of Biochemistry, Cairo University \\ ${ }^{2}$ Nutritional Chemistry Department, National Nutrition Institute \\ ${ }^{3}$ Nutritional Requirements and Growth Department, National Nutrition In stitute \\ ${ }^{4}$ Biochemistry Section, Faculty of Pharmaceutical Sciences and Pharmaceutical Industries, \\ Future University in Egypt, Future University
}

\begin{abstract}
Stunting represents a worldwide nutritional problem, which has many negative effects on child health and development. This study aimed to investigate the levels of insulin-like growth factor-1(IGF-1), total ghrelin and insulin resistance, as well as certain micronutrients affecting children growth and skeletal maturity in nutritionally stunted Egyptian children. Stunted children were selected to have height for age $\mathrm{Z}$ score $(\mathrm{HAZ})<-2$ standard deviation, whereas, control children were selected to have HAZ $>-2$. Stunted children were further classified according to weight for age $\mathrm{Z}$ score into normal and underweight groups. All stunted children exhibited significantly lower serum levels of IGF-1, Ca, and Mg compared to normal control children. Additionally, both normal weight and underweight groups showed insignificantly higher total ghrelin levels than the control values. Only stunted underweight children showed significantly lower serum Zn levels compared to control children. Meanwhile, no significant differences were observed in serum glucose and insulin levels, pancreatic beta cell function and insulin resistance between different study groups. In conclusion, these findings highlight the importance of early detection of abnormalities in growth hormone / IGF-1 axis and micronutrients levels in hope that appropriate intervention strategies could improve their status to obtain full growth potential in nutritionally stunted Egyptian children.
\end{abstract}

Received: 09 March 2019, Accepted: 30 June 2019

Key Words: Ghrelin; IGF-1; Insulin resistance; Micronutrient; Stunting.

Corresponding Author: Shimaa Metwally Abdou, BSc, National Nutrition Institute, 16 Kasr El Ainy Street, Cairo, 11562 , Egypt, Tel.: +20 1099515999, Fax: +2 02 224018119, Fax: +2 02 24018031, E-mail: dr_shmaa@yahoo.com

Bulletin of Faculty of Pharmacy, Cairo University, ISSN: 1110-0931, Vol. 57, No. 1

\section{INTRODUCTION}

Stunting or short stature is defined as having height-forage $\mathrm{z}$-score (HAZ) value of less than minus two standard deviations from the WHO Child Growth Standards median $^{[1]}$. It is estimated that about $22.9 \%$ of children under five years of age globally ${ }^{[2]}$, and $31 \%$ in Egypt $^{[3]}$, are stunted. Stunting is associated with increased morbidity, lower intelligence, reduced physical, neuro-developmental and economic capacity ${ }^{[4,5]}$.

Short stature can be classified into two main types: normal variant and pathological. Normal variant type includes familial and idiopathic short stature (ISS) as well as constitutional delay of growth and puberty (CDGP). Whereas, pathological short stature includes various causes such as malnutrition, genetic, and endocrine diseases ${ }^{[6]}$.

Growth hormone $(\mathrm{GH}) /$ insulin like growth factor-1 (IGF-1) axis is an important pathway in the regulation of linear growth ${ }^{[7]}$. IGF-1 is a hormone similar in molecular structure to proinsulin, and is produced primarily by the liver under the control of $\mathrm{GH}^{[8,9]}$. IGF-1 is affected by various factors such as nutrient intake and age ${ }^{[10]}$. One of IGF-1's principal functions is to mediate the growthpromoting effects of $\mathrm{GH}$ in peripheral tissues ${ }^{[11]}$. In contrast to pulsatile GH secretion, circulating IGF-1 is stable and reflects the long-term status of GH secretion ${ }^{[12]}$. Therefore, measurement of serum IGF-1 concentration can complement assessment of GH status in the investigation of short stature and contribute to prediction of growth response during GH therapy ${ }^{[7,13]}$.

Ghrelin is another component related to GH/IGF1 axis. It is a peptide hormone produced mainly in the stomach, and lower amounts can be derived from small intestine, pancreas, kidneys, and other organs ${ }^{[14]}$. Ghrelin was initially identified as the endogenous ligand of the $\mathrm{GH}$ secretagogue receptor in the brain, which is capable of 
stimulating GH release from the anterior pituitary gland. It acts as natural orexigenic factor and long-term body weight regulator, and has a role in glucose homeostasis, immunity, and cardio protection ${ }^{[15]}$. Consequently, ghrelin could affect growth by stimulating appetite and food intake and by altering GH secretion, subsequently affecting IGF-1 generation. Recently, it has been found that the total amount of fetal ghrelin levels is higher in comparison to the amount in adults which affirms its importance in prenatal life $\mathrm{e}^{[16]}$. Moreover, it was suggested that ghrelin may serve to stimulate appetite in small fetuses to adapt to intrauterine malnutrition ${ }^{[17,18]}$. Besides, there is accumulating preclinical and clinical evidence supporting a beneficial effect of ghrelin pathway inhibition for the treatment of type 2 diabetes $^{[19]}$.

Malnutrition in early life has been reported to impair the expression of several insulin-signaling proteins, which may represent early markers of insulin resistance and metabolic disease risk $^{[20]}$. However, conflicting results have been reported about the effects of undernutrition during childhood on glucose/insulin metabolism. A recent study demonstrated that the exposure to severe famine in the fetal or childhood period may predict a higher glycated haemoglobin $(\mathrm{HbAlc})$ and increased diabetes risk in adulthood $^{[21]}$. However, other studies demonstrated an insignificant change in glucose/ insulin axis in short stature children in South Africa ${ }^{[22]}$ and Germany ${ }^{[23]}$.

Furthermore, micronutrient malnutrition is known to be a major health burden in developing countries ${ }^{[24]}$. The child's brain is rapidly growing and has a high demand for energy, protein, essential fats, and key micronutrients, accordingly, deficiencies during this critical period may have long-term and irreversible effects on brain development ${ }^{[25,26]}$. It has been reported that inadequate intakes of zinc $(\mathrm{Zn})$, necessary in cellular replication and immune response development, are associated with impaired growth, diarrhea, delayed sexual maturation, and impaired appetite ${ }^{[27]}$.

Another essential element is calcium $(\mathrm{Ca})$ which is especially important in bone tissue, as it is an essential component of mineralized bone matrix, and cellular calcium signaling is a key process in the formation and repair of bones ${ }^{[28,29]}$.

On the other hand, magnesium $(\mathrm{Mg})$ is a crucial element that is implicated in all metabolic and biochemical processes in the cell, including energy metabolism, DNA replication, protein synthesis, and the control of cell proliferation ${ }^{[30]}$. Moreover, $\mathrm{Mg}$ deprivation has been reported to be associated with energetic and oxidative stress in several cell types ${ }^{[31,32]}$. Recently, Sargenti et al. ${ }^{[33]}$ showed that $\mathrm{Mg}$ deprivation modulates stem cell plasticity and differentiation potential.

To the best of our knowledge, little information is available about serum levels of IGF-1 and total ghrelin in nutritionally stunted Egyptian children. Therefore, the present study was undertaken to investigate the possible changes in the level of these crucial hormones, and to assess insulin levels and pancreatic beta cell function, as well as the levels of certain essential micronutrients in nutritionally stunted Egyptian children in a trial for the early identification of growth abnormalities to prevent their possible harmful effects in the future.

\section{METHODS}

\subsection{Participants}

The study included 87 pre-pubertal children classified according to HAZ into 59 stunted (HAZ $<-2$ standard deviation score (SDS)), and 28 healthy control (HAZ > -2 SDS) during the period from November 2013 to March 2014. The stunted children (aged from 4 to 10 years) were recruited from the stunting outpatient clinic of the National Nutrition Institute, Cairo, Egypt. The stunted group was further subdivided according to weight for age Z score (WAZ) into two groups, normal weight-stunted (WAZ > -2 SDS), and underweight-stunted children (WAZ < -2 SDS). Children with hypothyroidism and/ or suffering from chronic cardiovascular, respiratory or urinary system diseases, as well as children with complaints of the gastrointestinal tract were excluded from the study. The control group was selected from healthy children aged from 4.9 to 9.5 years. They were chosen to have normal weight and height, as well as normal history of growth and development.

The stunted children and the control ones were subjected to full history including age, sex, previous diseases, operations, history of drug intake. Weight was measured to the nearest $0.1 \mathrm{~kg}$ using an electronic digital scale, and height was measured to the nearest $0.1 \mathrm{~cm}$ using a stadiometer, then the body mass index (BMI) was calculated using the following formula: $\mathrm{BMI}=$ weight $(\mathrm{kg})$ /height $(\mathrm{m}) 2$. HAZ, WAZ, and BMI-for-age Z-scores (BMIZ) were calculated for each child with the use of World Health Organization's AnthroPlus software ${ }^{[34]}$. The Clinical examination was performed by a physician and routine investigation including complete blood picture, urine and stool analyses were done. The study was conducted according to the Declaration of Helsinki Principles, and was approved by the Research Ethics Committee for Experimental and Clinical Studies of the Faculty of Pharmacy, Cairo University (approval number BC 777), and by that of the National Organization for Teaching Hospitals and Institutes (approval number IN000065). Written informed consent was obtained from the parents of each participant after the nature of the procedures had been explained.

\subsection{Biochemical analyses}

Five milliliters of blood were collected in a clean tube after $12 \mathrm{~h}$ of overnight fasting. Serum was obtained by centrifugation at $3000 \mathrm{rpm}$ for $15 \mathrm{~min}$ in a refrigerated centrifuge. Samples were processed as quickly as possible and kept on ice. The separated sera were divided into five portions. One was immediately used to determine serum 
glucose level, and the other four portions were stored at $-20^{\circ} \mathrm{C}$ for subsequent laboratory investigations.

\subsubsection{Estimation of IGF-1, total ghrelin and insulin}

IGF-1 was measured by solid phase competitive ELISA kit (DRG International inc., USA), while total ghrelin and insulin were measured by solid phase sandwich ELISA kits (Glory Science Co., Ltd, USA, and DRG International inc., USA, respectively) according to the manufacturers' instructions.

\subsubsection{Estimation of glucose}

Glucose was measured by colorimetric enzyme method described by Trinder $^{[35]}$ using Stanbio laboratory kit (USA).

\subsubsection{Assessment of pancreatic beta cell function and insulin resistance}

The homeostasis model assessment version 2 (HOMA2) was used to evaluate pancreatic beta cell function (HOMA2-\%B) and insulin resistance (HOMA2-IR) from the paired fasting glucose and insulin concentrations using HOMA2 calculator version 2.2 $2^{[36]}$. Results were expressed as a percentage of the normal reference population.

\subsubsection{Estimation of $\mathrm{Ca}, \mathrm{Mg}$, and $\mathrm{Zn}$}

$\mathrm{Ca}$ level was determined according to the method of Gindler and King ${ }^{[37]}$ using Biosystems S.A. kit (Spain). Mg level was measured according to the method of Mann and Yoe $^{[38]}$ using Spectrum Diagnostics kit (Egypt). Zn level was measured according to the method of Homsher and $\mathrm{Zak}^{[39]}$ using Quimica Clinica Aplicada kit (Spain).

\subsection{Statistical analyses}

The data were analyzed using the computer based statistical package of statistical product and service solutions (SPSS version 20.0, SPSS Inc. Chicago, IL, USA). All the data are expressed as mean \pm standard error of mean (SEM). One way ANOVA (post hoc; Tuckey test) was applied in the evaluation of normally distributed variables. Non parametric Kruskal-Wallis test was used when necessary. The relationship between IGF-1, ghrelin, and minerals with different measured parameters were done using the bivariate correlation by the use of Spearman correlation coefficient. $P$-value of $<0.05$ was considered significant. Multiple regression analyses were done with standardized coefficients and values of $P<0.05$ were considered statistically significant.

\section{RESULTS}

\subsection{Anthropometric characteristics}

Anthropometric characteristics of all groups were summarized in (Table 1). There was no significant difference in age between different studied groups. Stunted normal and underweight children exhibited significantly lower weight, height, WAZ and HAZ compared to control children. Stunted normal weight children showed significantly higher BMI and BMIZ, while stunted underweight children showed significantly lower values for these two parameters compared to control values. Moreover, stunted underweight children had significantly lower WAZ, BMI, and BMIZ compared to the stunted normal weight children.

Table 1: Anthropometric characteristics and minerals levels of different study groups

\begin{tabular}{|c|c|c|c|}
\hline Parameters & $\begin{array}{l}\text { Control } \\
\text { children } \\
(n=28)\end{array}$ & $\begin{array}{c}\text { Stunted } \\
\text { normal weight } \\
\text { children } \\
(\mathrm{n}=29)\end{array}$ & $\begin{array}{l}\text { Stunted } \\
\text { underweight } \\
\text { children } \\
(\mathrm{n}=30)\end{array}$ \\
\hline Age (years) & $\begin{array}{c}7 \pm 0.3 \\
(4.9-9.5)\end{array}$ & $\begin{array}{c}6.8 \pm 0.4 \\
(4.2-10)\end{array}$ & $\begin{array}{c}7.1 \pm 0.3 \\
(4-10)\end{array}$ \\
\hline $\operatorname{Sex}(\mathrm{M} / \mathrm{F})$ & $(15 / 13)$ & $(14 / 15)$ & $(13 / 17)$ \\
\hline Weight (kg) & $\begin{array}{c}21.4 \pm 0.9 \\
(15.5-32.8)\end{array}$ & $\begin{array}{c}18.6 \pm 0.7^{*} \\
(14-26)\end{array}$ & $\begin{array}{l}16.3 \pm 0.6^{* \star} \\
(11.5-21)\end{array}$ \\
\hline Height $(\mathrm{cm})$ & $\begin{array}{c}116.5 \pm 1.9 \\
(101.5-136.2)\end{array}$ & $\begin{array}{c}103.4 \pm 1.53^{*} \\
(91.5-121)\end{array}$ & $\begin{array}{c}104.8 \pm 1.71^{*} \\
(87.7-119.5)\end{array}$ \\
\hline WAZ & $\begin{array}{c}-0.6 \pm 0.1 \\
(-1.8-0.8)\end{array}$ & $\begin{array}{c}-1.4 \pm 0.1^{*} \\
(-1.97-0.08)\end{array}$ & $\begin{array}{c}-2.6 \pm 0.1^{* ๘} \\
(-3.8--2.1)\end{array}$ \\
\hline HAZ & $\begin{array}{c}-0.9 \pm 0.2 \\
(-1.98-1.73)\end{array}$ & $\begin{array}{c}-2.9 \pm 0.1^{*} \\
(-4.2--2.2)\end{array}$ & $\begin{array}{c}-3.2 \pm 0.1^{*} \\
(-4.7--2.3)\end{array}$ \\
\hline BMI (kg/m2) & $\begin{array}{c}15.5 \pm 0.2 \\
(14-17.7)\end{array}$ & $\begin{array}{c}16.8 \pm 0.2^{*} \\
(14.9-19.6)\end{array}$ & $\begin{array}{c}14.8 \pm 0.1^{* \Phi} \\
(12.9-16.7)\end{array}$ \\
\hline BMIZ & $\begin{array}{c}-0.1 \pm 0.1 \\
(-1.3-0.8)\end{array}$ & $\begin{array}{c}0.7 \pm 0.1^{*} \\
(-0.5-2.2)\end{array}$ & $\begin{array}{l}-0.6 \pm 0.1^{* \pi} \\
(-2.3-0.5)\end{array}$ \\
\hline $\begin{array}{l}\mathrm{Ca} \\
(\mathrm{mmol} / \mathrm{l})\end{array}$ & $\begin{array}{l}2.6 \pm 0.02 \\
(2.3-2.8)\end{array}$ & $\begin{array}{l}2.2 \pm 0.04^{*} \\
(1.9-2.6)\end{array}$ & $\begin{array}{l}2.3 \pm 0.04^{*} \\
(1.8-2.7)\end{array}$ \\
\hline $\begin{array}{l}\mathrm{Mg} \\
(\mathrm{mmol} / 1)\end{array}$ & $\begin{array}{l}1.3 \pm 0.04 \\
(0.8-1.6)\end{array}$ & $\begin{array}{l}0.8 \pm 0.07^{*} \\
(0.3-1.5)\end{array}$ & $\begin{array}{l}0.9 \pm 0.05^{*} \\
(0.3-1.5)\end{array}$ \\
\hline $\begin{array}{l}\mathrm{Zn} \\
(\mu \mathrm{moI} / 1)\end{array}$ & $\begin{array}{c}25.6 \pm 0.2 \\
(23.4-28.1)\end{array}$ & $\begin{array}{c}24.5 \pm 0.7 \\
(14.3-28.9)\end{array}$ & $\begin{array}{c}23.1 \pm 0.5^{* ๘} \\
(14.2-28.3)\end{array}$ \\
\hline
\end{tabular}

Data are expressed as mean \pm SEM, range is stated between parentheses.

BMI, body mass index; BMIZ, body mass index-for-age Z score; HAZ, height-for-age $\mathrm{Z}$ score; WAZ: weight-for-age $\mathrm{Z}$ score; $\mathrm{Ca}$, calcium; $\mathrm{Mg}$, magnesium; Zn, zinc.

*Significant difference from control group at $P<0.05$, I significant difference from stunted normal weight group at $P<0.05$.

\subsection{IGF-1 and total ghrelin levels}

As shown in (Figure 1), stunted normal and underweight children showed significantly lower IGF-1 levels than control children $(138.7 \pm 11.7 \mathrm{ng} / \mathrm{ml}, 118.9 \pm 9.4 \mathrm{ng} / \mathrm{ml}$, $182.2 \pm 15.1 \mathrm{ng} / \mathrm{ml}$, respectively). On the other hand, results presented in (Figure 2) indicated that serum total ghrelin levels of the stunted normal and underweight children were insignificantly higher than those of control ones $(1244.5 \pm 124.2 \mathrm{ng} / \mathrm{l}, 1317.7 \pm 146.9 \mathrm{ng} / \mathrm{l}, 1046.4 \pm 91.1$ ng/l, respectively). 


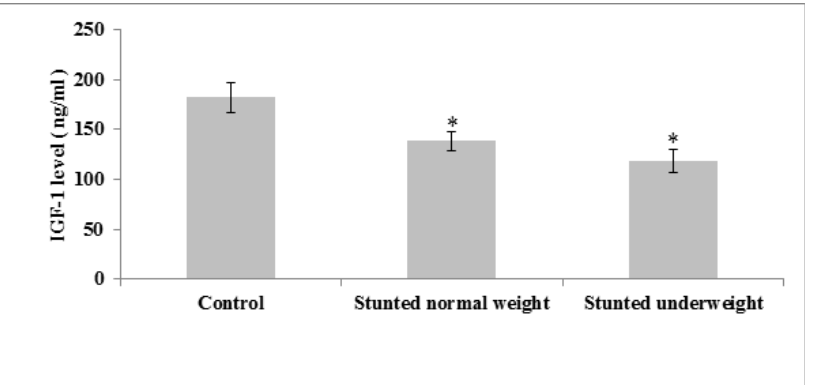

Fig. 1: Serum IGF-1 levels in different studied groups. Data are expressed as mean \pm SEM. * Significant difference from the control group at $p<0.05$

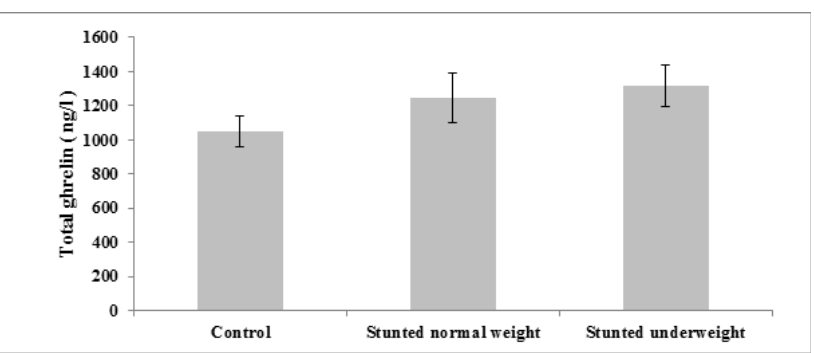

Fig. 2: Serum total ghrelin levels in different studied groups. Data are expressed as mean \pm SEM

(a)

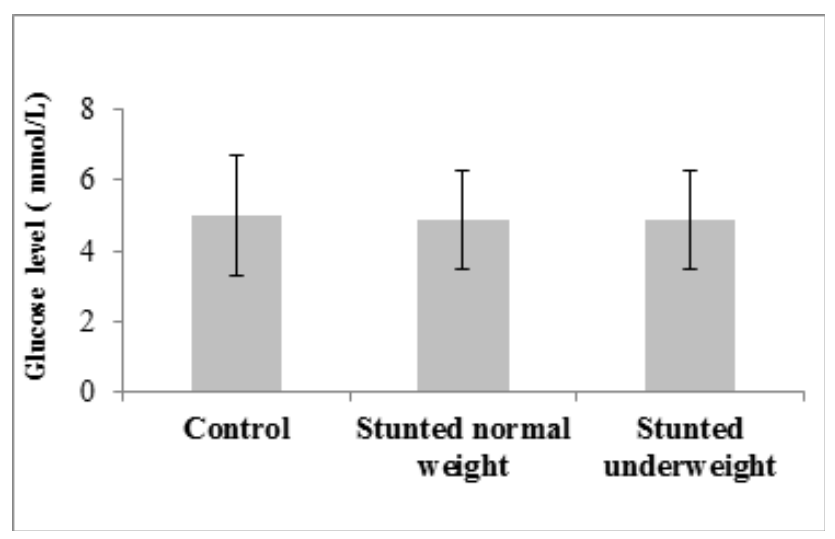

(c)

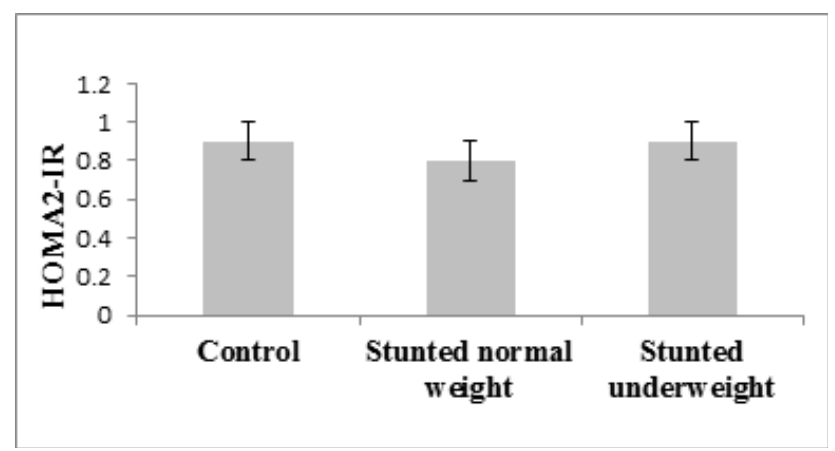

Fig. 3: Glucose- insulin axis in different studied groups.

(a) Serum glucose levels

(b) Serum insulin levels

(c) homeostasis model assessment of insulin resistance (HOMA2-IR)

(d) homeostasis model assessment of pancreatic beta cell function (HOMA2-\%B)

\subsection{Pancreatic beta cell function and insulin resistance:}

Data presented in (Figure 3) indicated that there were no significant differences in the serum levels of glucose (Figure 3a), insulin (Figure 3b), insulin resistance (Figure 3c) and pancreatic beta cell function (Figure 3d) in different studied groups.

\subsection{Ca, Mg, and Zn levels:}

Stunted normal and underweight children exhibited significantly lower $\mathrm{Ca}$ (Figure 4a) and $\mathrm{Mg}$ (Figure 4b) levels compared to control group. Furthermore, serum $\mathrm{Ca}$ levels of stunted underweight children were significantly higher than those of stunted normal weight (Figure 4a). Meanwhile, serum $\mathrm{Zn}$ levels of stunted underweight children were significantly lower compared to stunted normal weight and control children (Figure 4c). (b)

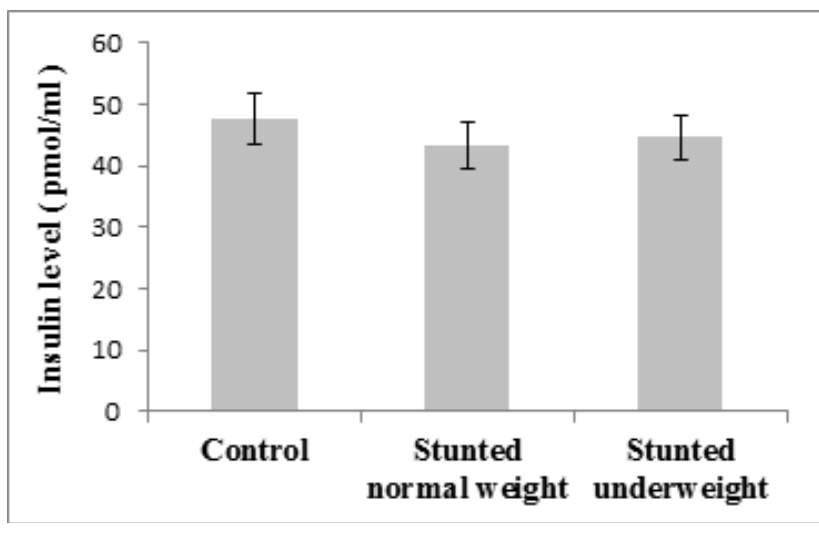

(d)

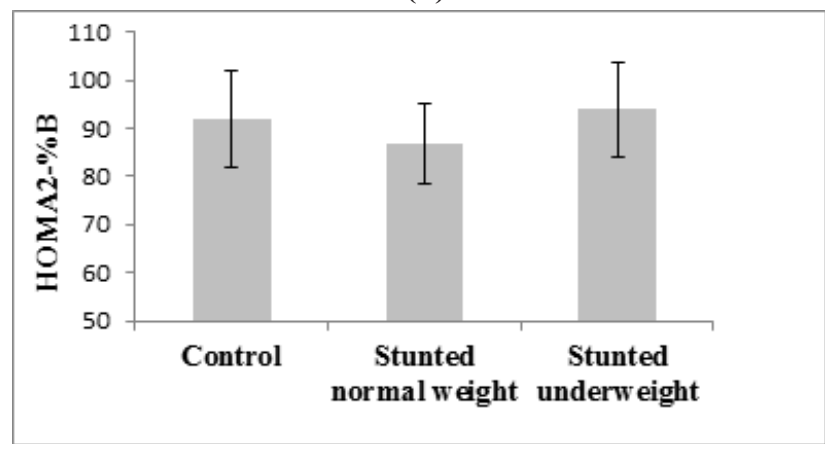


(a)

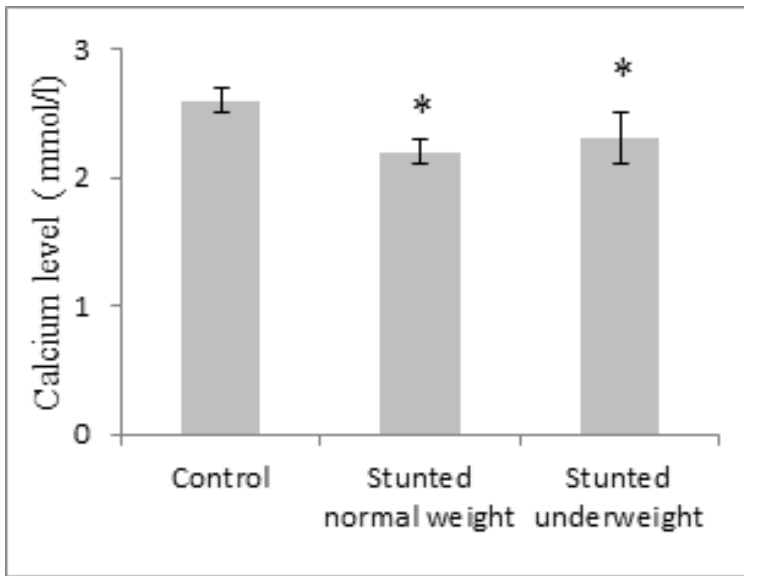

(b)

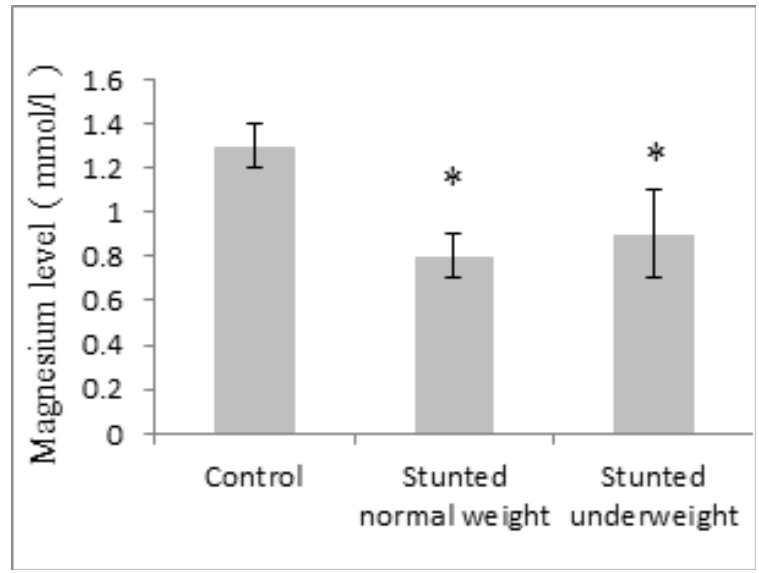

(c)

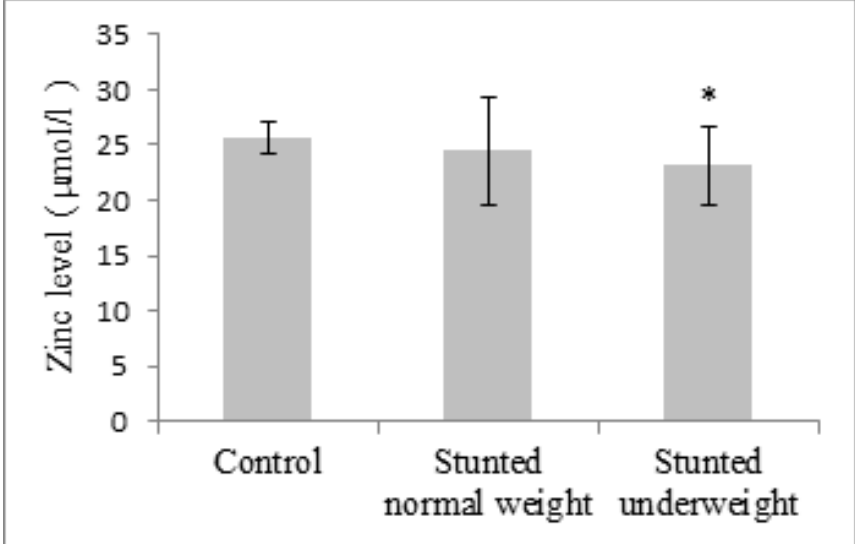

Fig. 4: Serum minerals levels in different studied groups.

(a) Serum Ca levels

(b) Serum Mg levels

(c) Serum Zn levels

* Significant difference from the control group at $p<0.05$

3.5 Correlation of IGF-1, total ghrelin, and micronutrients levels with the anthropometric and biochemical parameters:

Results in (Table 2) showed that IGF-1 exhibited significant positive correlation with age, weight, and height in both stunted groups. However, IGF-1 showed significant positive correlation with $\mathrm{HAZ}$ in stunted underweight children only. No significant correlations were detected between total ghrelin and any of the studied anthropometric or biochemical variables in the two stunted groups. In stunted normal weight children, serum $\mathrm{Mg}$ showed significant negative correlation with glucose (correlation coefficient $(\mathrm{r})=-0.4, p$ value $=0.03)$. While, serum $\mathrm{Zn}$ and $\mathrm{Ca}$ did not show significant correlations with any of the measured parameters. 
Table 2: Correlation between IGF-1 and the measured parameters in the stunted groups

\begin{tabular}{lcccc}
\hline \multirow{2}{*}{ Parameters } & \multicolumn{2}{c}{$\begin{array}{c}\text { Stunted normal } \\
\text { weight children }\end{array}$} & $\begin{array}{c}\text { Stunted underweight } \\
\text { children }\end{array}$ \\
\cline { 2 - 5 } & $\begin{array}{c}\text { Correlation } \\
\text { coefficient }(\mathrm{r}=)\end{array}$ & $P$-value & $\begin{array}{c}\text { Correlation } \\
\text { coefficient }(\mathrm{r}=)\end{array}$ & $P$-value \\
\hline Age & 0.530 & $0.004^{*}$ & 0.611 & $<0.001^{*}$ \\
Weight & 0.477 & $0.010^{*}$ & 0.645 & $<0.001^{*}$ \\
Height & 0.469 & $0.012^{*}$ & 0.685 & $<0.001^{*}$ \\
BMI & 0.057 & 0.773 & -0.023 & 0.903 \\
WAZ & -0.077 & 0.699 & 0.167 & 0.378 \\
HAZ & -0.136 & 0.491 & 0.449 & $0.013^{*}$ \\
BMIZ & -0.135 & 0.493 & -0.326 & 0.078 \\
Glucose & 0.081 & 0.682 & -0.184 & 0.330 \\
Insulin & 0.186 & 0.344 & 0.072 & 0.706 \\
HOMA2-\%B & 0.082 & 0.674 & 0.100 & 0.599 \\
HOMA2-IR & 0.337 & 0.074 & -0.111 & 0.558 \\
Total ghrelin & -0.090 & 0.649 & -0.055 & 0.773 \\
Zn & 0.250 & 0.191 & 0.101 & 0.596 \\
Ca & 0.020 & 0.920 & 0.233 & 0.215 \\
Mg & 0.165 & 0.393 & 0.148 & 0.435 \\
\hline
\end{tabular}

* Significant correlation at $p<0.05$

BMI, body mass index; BMIZ, body mass index-for-age $\mathrm{Z}$ score; Ca, calcium; HAZ, height-for-age Z score; HOMA2-\%B, homeostasis model assessment of pancreatic beta cell function; HOMA2-IR, homeostasis model assessment of insulin resistance; $\mathrm{Mg}$, magnesium; WAZ, weightfor-age Z score; Zn, zinc.

\subsection{Multiple regression of IGF-1 with the measured parameters in the stunted groups}

On performing multiple regression, it was demonstrated that height is a significant predictor of IGF-I in the stunted underweight children group only $(\beta=-8.38, p=0.022)$. No significant predictors were observed in the stunted normal weight group.

\section{DISCUSSION}

The main findings of the current study indicated that stunted Egyptian children, both normal and underweight, exhibited significantly lower levels of serum IGF-1 along with insignificantly higher total ghrelin levels. No change was observed in serum levels of glucose and insulin, beta cell function, and insulin resistance in both stunted children groups compared to the control ones. Moreover, normal and underweight stunted children demonstrated significantly lower levels of serum $\mathrm{Ca}$ and $\mathrm{Mg}$, whereas only stunted underweight children showed significantly lower serum $\mathrm{Zn}$ levels.

One of the most evident consequences of undernutrition is the restriction of linear growth, which is mainly a result of GH-IGF-I axis disruption ${ }^{[40]}$. In the present study, nutritionally stunted Egyptian children showed significantly lower serum IGF-1 levels. This observation is in harmony with the study of Metwalley et al. ${ }^{[41]}$ in which Egyptian children with short stature and GH deficiency exhibited significantly lower IGF-1 levels. It also agreed with the work of Hamza et al. ${ }^{[42]}$ who demonstrated that serum IGF1 levels were significantly low in short Egyptian children with $\mathrm{Zn}$ deficiency.

Our results also in accordance with the decreased IGF-1 levels in the serum of French pre-pubertal children with ISS $^{[43]}$ and the reported lower IGF-1 levels in severely stunted undernourished Brazilian children compared to moderately stunted children $^{[44]}$. Likewise, Stawerska et al. ${ }^{[45]}$ found that IGF-1 levels were significantly lower in short thin Polish children with ISS compared to the control group. On the same line, DeBoer et al. ${ }^{[46]}$ reported insignificantly lower serum IGF-1 levels in stunted malnourished Brazilian children compared to non-stunted counterparts.

In fact, GH-driven linear growth can only occur when GH can induce IGF-1 and other paracrine growth factors as a result of the appropriate dietary signaling from key nutrients, such as essential amino acids and $\mathrm{Zn}^{[47]}$. Besides, it has been suggested that decreased plasma IGF-1 levels during the periods of undernutrition may be a part of the body's effort to adapt by shunting calories away from nonessential processes including growth ${ }^{[48]}$. Moreover, undernutrition can affect linear growth by various mechanisms including reduction of GH and IGF-1 receptors ${ }^{[49]}$ and increasing fibroblast growth factor 21 levels that inhibit GH binding and action in the epiphyseal growth plate ${ }^{[50]}$. Additionally, malnutrition induces sirtuin-1, a nutritionally responsive protein, that blocks the JAK/STAT pathway and inhibits $\mathrm{GH}$ signal transduction in the liver ${ }^{[51]}$. Furthermore, it has been shown that malnutrition causes a reduction in microRNA-21 that promotes chondrocyte proliferation and bone matrix synthesis ${ }^{[52]}$. Interestingly, increased levels of IGF-1 and HAZ were observed in stunted Brazilian prepubertal children after nutritional treatment ${ }^{[53]}$.

In the current study, IGF-1 showed significant positive correlations with age, weight and height in both stunted children groups and with HAZ in stunted underweight children. These observations are in harmony with the study of Camurdan et al. ${ }^{[54]}$ which demonstrated that serum IGF-1 values were significantly correlated with age, weight, height, and height SDS in Turkish children with familial short stature. Similarly, DeBoer et al. ${ }^{[46]}$ reported that IGF-1 was positively associated with HAZ and WAZ in Brazilian malnourished children. Furthermore, Wang et $a l .{ }^{[55]}$ demonstrated a significant positive correlations between the level of IGF-1, height, weight, and age in Chinese children with ISS.

Ghrelin is a potent stimulator of GH secretion from the pituitary ${ }^{[56,57]}$, and it has been found to be the most powerful orexigenic peptide ${ }^{[58]}$. Results of the present study demonstrated that serum total ghrelin levels were insignificantly higher in the both stunted groups compared to the control group. Such observation agreed with previous studies which demonstrated insignificant difference in serum total ghrelin levels of Turkish children with 
$\mathrm{CDGP}^{[59]}$, in short stature children in $\mathrm{USA}^{[60]}$, as well as in Iranian children with ISS $^{[61]}$ compared to control group. Our results are also in harmony with earlier reports in which significantly higher ghrelin levels were reported in the serum of Turkish short stature children with $\mathrm{CDGP}^{[54]}$, and malnourished Turkish children ${ }^{[62]}$, as well as in Polish short thin children ${ }^{[45]}$ compared to control group.

It has been suggested that ghrelin levels might be elevated in Turkish short stature children with CDGP in a compensatory manner due to its orexigenic and strong $\mathrm{GH}$ secretagogue functions as a response to lowered body weight and height $\operatorname{SDS}^{[54]}$. Actually, ghrelin can act both directly on the pituitary to stimulate GH release by binding to GHSR1a and by acting on hypothalamus and vagus nerve ${ }^{[63]}$. Moreover, ghrelin analogs have been demonstrated to possess a potential beneficial effects in the treatment of GH-deficiency disorders ${ }^{[64]}$.

Our data also indicated that no correlation was observed between total ghrelin levels and IGF-1 or anthropometric measurements. These findings are in accordance with the study of Pinsker et al. ${ }^{[60]}$ who reported that height, weight, and BMI z-scores did not correlate with ghrelin levels in short stature children in USA. Similarly, there was no significant correlation between ghrelin, growth hormone, IGF-1 levels, bone age and BMI in Iranian children with ISS $^{[61]}$.

In the present study, serum levels of glucose, insulin, Beta cell function, and insulin resistance of all, normal and underweight, stunted children did not differ significantly from the control ones, suggesting lack of simple relationship between stunting and predisposition to diabetes among studied stunted Egyptian children. These results are in harmony with the findings of Mamabolo et al. ${ }^{[22]}$ in which no significant difference was found in serum levels of glucose, insulin, Beta cell function, and insulin resistance in stunted South African children. On the same line, short German children exhibited insignificant changes in glucose, insulin, HOMA-IR compared to normal height children ${ }^{[23]}$.

On the contrary, decreased values of serum insulin and Beta cell function has been demonstrated in stunted Brazilian children ${ }^{[65]}$. Additionally, a recent study showed the presence of insulin resistance among Indian undernourished rural population that was improved after six months of food supplementation ${ }^{[66]}$. On the other hand, Clemente et al. ${ }^{[67]}$ observed higher serum insulin levels in stunted Brazilian children. These inconsistent findings could be due to different degree of malnutrition, ethnicity, age ranges of participants, pubertal stage, body weight status, as well as methods of biochemical analyses.

In the current investigation, serum $\mathrm{Ca}$ and $\mathrm{Mg}$ levels were significantly lower in both stunted groups compared to control group. These observations are in accordance with the those of Khairy et al. ${ }^{[68]}$ in which nutritionally stunted Egyptian children exhibited significantly lower serum $\mathrm{Ca}$ and $\mathrm{Mg}$ levels compared to control group. Likewise, significantly lower serum $\mathrm{Mg}^{[69]}$ and serum $\mathrm{Ca}^{[70]}$ levels were demonstrated in nutritionally stunted Egyptian children and in stunted Chinese children, respectively. Actually, it has been reported that stunting and associated micronutrient deficiencies can cause permanent loss of growth and can lead to long term deficits in mental capacity in Pakistani malnourished stunted children ${ }^{[71]}$. Additionally, dietary $\mathrm{Ca}$ deficiency results in reduced serum $\mathrm{Ca}$ and increased parathyroid hormone (PTH) levels which increase bone resorption and osteoclast activity leading to bone $\operatorname{loss}^{[72]}$.

On the other hand, an important role for $\mathrm{Mg}$ in vitamin $\mathrm{D}$ activation and function as well as in bone metabolism has been reported. Thus, Mg deficiency was found to be associated with various disorders, such as skeletal deformities and osteoporosis ${ }^{[73,74]}$. Moreover, Mg deficiency may give rise to alterations in glucose metabolism, since $\mathrm{Mg}$ plays an important role in carbohydrate metabolism and insulin response, as a cofactor involved in transmembrane transport of glucose and release of insulin ${ }^{[75,76]}$. Studies have found that $\mathrm{Mg}$ deficiency is usually associated with endocrine and metabolic disorders, especially type 2 diabetes mellitus ${ }^{[77]}$. Indeed, this was evidenced in the current study by a significant negative correlation between $\mathrm{Mg}$ and glucose levels. Our finding is in accordance with the study of Bo et al. ${ }^{[78]}$ who found significant negative correlation between dietary $\mathrm{Mg}$ intake and serum glucose levels in Italian pre-school children born with very low birth weight. It is also in harmony with the study of Shahbah et al. ${ }^{[79]}$ in which Egyptian children with type-1 diabetes showed significant negative correlation between $\mathrm{Mg}$ and glucose .

In current study, the observation that stunted underweight children exhibited significantly lower serum Zn level agreed with the reports of Aly et al. ${ }^{[80]}$ in which nutritionally stunted Egyptian children showed significantly lower serum $\mathrm{Zn}$ levels, and that of Marasinghe et al. ${ }^{[1]}$ in severely stunted and severely underweight Sri Lankan children compared to control group. In fact, the role of $\mathrm{Zn}$ in growth had been explained through its influence on the GH/IGF-1 system, thus Hamza et al. ${ }^{[42]}$ reported that Egyptian children with short stature and $\mathrm{Zn}$ deficiency demonstrated significant increases in serum IGF-1, and height SDS after 3 months of $\mathrm{Zn}$ supplementation. The authors suggested that the growth stimulating effect of $\mathrm{Zn}$ might be mediated through changes in circulating IGF-1 levels.

In conclusion, our findings highlight the importance of early detection of abnormalities in GH /IGF-1 axis and micronutrients levels in hope that appropriate intervention strategies could improve their status to obtain full growth potential in nutritionally stunted Egyptian children.

\section{CONFLICT OF INTEREST}

There are no conflicts of interest. 


\section{REFERENCES}

1. M. Onis, WHO Child Growth Standards based on length/height, weight and age, Acta paediatrica 95 (2006) 76-85.

2. C. Hayashi, J. Krasevec, R. Kumapley, et al., Levels and trends in child malnutrition. UNICEF/WHO/World Bank Group joint child malnutrition estimates: key findings of the 2017 edition. Downloaded from: http://www. who.int/nutgrowthdb/jme_brochoure2017.pdf. Date accessed: 6/10/2018., (2017)

3. Egypt Demographic and Health Survey, Ministry of Health and Population (Egypt), El-Zanaty and Associates (Egypt), and ICF International.Egypt Demographic and Health Survey 2014. Cairo, Egypt and Rockville, Maryland, USA: Ministry of Health and Population and ICF International (2015). Downloaded from: https://dhsprogram. com/pubs/pdf/FR313/FR.313.pdf. Date accessed: $11 / 1 / 2019$

4. A.J. Prendergast, J.H. Humphrey, The stunting syndrome in developing countries, Paediatrics and international child health 34 (2014) 250-265.

5. B.L. Horta, C.G. Victora, C.L. de Mola, et al., Associations of linear growth and relative weight gain in early life with human capital at 30 years of age, The Journal of pediatrics 182 (2017) 85-91.

6. S. Yadav, A. Dabas, Approach to short stature, The Indian Journal of Pediatrics 82 (2015) 462-470.

7. W. Blum, A. Alherbish, A. Alsagheir, et al., The growth hormone-insulin-like growth factor-I axis in the diagnosis and treatment of growth disorders, Endocrine connections (2018) EC-18-0099.

8. A.D. Bakker, R.T. Jaspers, IL-6 and IGF-1 signaling within and between muscle and bone: how important is the mTOR pathway for bone metabolism?, Current osteoporosis reports 13 (2015) 131-139.

9. C. Schmid, Insulin-like growth factors, Cell biology international 19 (1995) 445-457.

10. D.R. Clemmons, Metabolic actions of insulinlike growth factor-1 in normal physiology and diabetes, Endocrinology and metabolism clinics of North America 41 (2012) 425-443.

11. J.I. Jones, D.R. Clemmons, Insulin-like growth factors and their binding proteins: biological actions, Endocrine reviews 16 (1995) 3-34.

12. J. Lepenies, Z. Wu, P.M. Stewart, C.J. Strasburger, M. Quinkler, IGF-1, IGFBP-3 and ALS in adult patients with chronic kidney disease, Growth hormone and IGF research 20 (2010) 93-100.

13. E. Schonau, F. Westermann, F. Rauch, et al., A new and accurate prediction model for growth response to growth hormone treatment in children with growth hormone deficiency, European Journal of Endocrinology 144 (2001) 13-20.

14. S. Yanagi, T. Sato, K. Kangawa, M. Nakazato, The Homeostatic Force of Ghrelin, Cell metabolism (2018) 786-804.

15. L. Šaranac, Z. Gucev, The ghrelin system; beyond the role in energy homeostasis, Facta universitatisseries: Medicine and Biology 18 (2016) 33-38.

16. M. Warchol, H. Krauss, M. Wojciechowska, et al., The role of ghrelin, leptin and insulin in foetal development, Annals of agricultural and environmental medicine : AAEM 21 (2014) 349-352.

17. M.I. González-Domínguez, M.-L. Lazo-de-laVega, S. Zaina, et al., Association of cord blood des-acyl ghrelin with birth weight, and placental GHS-R1 receptor expression in SGA, AGA, and LGA newborns, Endocrine 53 (2016) 182-191.

18. A. Dessi, C. Pravettoni, F. Cesare Marincola, A. Schirru, V. Fanos, The biomarkers of fetal growth in intrauterine growth retardation and large for gestational age cases: from adipocytokines to a metabolomic all-in-one tool, Expert review of proteomics 12 (2015) 309-316.

19. A.L. Poher, M.H. Tschop, T.D. Muller, Ghrelin regulation of glucose metabolism, Peptides 100 (2018) 236-242.

20. L. Berends, D. Fernandez-Twinn, M. MartinGronert, R. Cripps, S. Ozanne, Catch-up growth following intra-uterine growth-restriction programmes an insulin-resistant phenotype in adipose tissue, International Journal of Obesity 37 (2013) 1051-1057.

21. N. Wang, J. Cheng, B. Han, et al., Exposure to severe famine in the prenatal or postnatal period and the development of diabetes in adulthood: an observational study, Diabetologia 60 (2017) 262-269.

22. R.L. Mamabolo, M. Alberts, N.S. Levitt, H.A. Delemarre-van de Waal, N.P. Steyn, Association between insulin-like growth factor-1, insulin-like growth factor-binding protein-1 and leptin levels with nutritional status in 1-3-year-old children, residing in the central region of Limpopo Province, South Africa, The British journal of nutrition 98 (2007) 762-769.

23. M.B. Ranke, R. Schweizer, S.M. Rodemann, et al., School children born VLBW or VLGA show heightrelated changes in body composition and muscle 
function but no evidence of metabolic syndrome risk factors. Results from the NEOLONG study, Journal of pediatric endocrinology and metabolism 29 (2016) 163-172.

24. K.K. Sharma, S.R. Dumbala, P. Bhatnagar-Mathur, Biotech approaches for crop improvement in the semi-arid tropics, Plant Biotechnology, Springer (2014) pp. 193-207.

25. S.P. Walker, S.M. Chang, C.A. Powell, E. Simonoff, S.M. Grantham-McGregor, Early childhood stunting is associated with poor psychological functioning in late adolescence and effects are reduced by psychosocial stimulation, The Journal of nutrition 137 (2007) 2464-2469.

26. P.H. Nguyen, A.M. DiGirolamo, I. GonzalezCasanova, et al., Influences of early child nutritional status and home learning environment on child development in Vietnam, Maternal and child nutrition 14 (2018) 1-11.

27. A.L. Wani, N. Parveen, M.O. Ansari, M.F. Ahmad, S. Jameel, G. Shadab, Zinc: An element of extensive medical importance, Current Medicine Research and Practice 7 (2017) 90-98.

28. M. Peacock, Calcium metabolism in health and disease, Clinical Journal of the American Society of Nephrology 5 (2010) S23-S30.

29. E. O’Neill, G. Awale, L. Daneshmandi, O. Umerah, K.W.-H. Lo, The roles of ions on bone regeneration, Drug discovery today 23 (2018) 879-890.

30. S. Long, A.M. Romani, Role of cellular magnesium in human diseases, Austin journal of nutrition and food sciences 2 (2014) 1051-1060

31. B. Barbiroli, S. Iotti, R. Lodi, Improved brain and muscle mitochondrial respiration with CoQ. An in vivo study by^ $\left.{ }^{\wedge} 31\right\}$ P-MR spectroscopy in patients with mitochondrial cytopathies, Biofactors 9 (1999) 253-260.

32. R. Vink, M. Nechifor, Magnesium in the Central Nervous System, University of Adelaide Press (c). Adelaide (AU), 2011

33. A. Sargenti, S. Castiglioni, E. Olivi, et al., Magnesium Deprivation Potentiates Human Mesenchymal Stem Cell Transcriptional Remodeling, International journal of molecular sciences 19 (2018) 1-13.

34. AnthroPlus for personal computers, WHO Software for assessing growth of the world's children and adolescents, Downloaded from http:/ www.who.int/growthref/tools/en/. Date accessed: 21/6/2018. (2009).

35. P. Trinder, Determination of blood glucose using 4-amino phenazone as oxygen acceptor, Journal of clinical pathology 22 (1969) 246.

36. T.M. Wallace, J.C. Levy, D.R. Matthews, Use and abuse of HOMA modeling, Diabetes care 27 (2004) 1487-1495.

37. E.M. Gindler, J.D. King, Rapid colorimetric determination of calcium in biologic fluids with methylthymol blue, American journal of clinical pathology 58 (1972) 376-382.

38. C.K. Mann, J.H. Yoe, Spectrophotometric determination of magnesium with 1-azo-2hydroxy-3-(2.4-dimethylcarboxanilido)-naphthalene-1-(2-hydroxybenzene), Analytica chimica acta 16 (1957) 155-160.

39. R. Homsher, B. Zak, Spectrophotometric investigation of sensitive complexing agents for the determination of zinc in serum, Clinical chemistry 31 (1985) 1310-1313.

40. V.J.B. Martins, M.P. de Albuquerque, A.L. Sawaya, Endocrine changes in undernutrition, metabolic programming, and nutritional recovery. In: Handbook of famine, starvation, and nutrient deprivation: From biology to policy (Preedy, V. and Patel, V. B., eds), Cham: Springer International Publishing ( 2017) pp 1-21.

41. K.A. Metwalley, H.S. Farghaly, H.A.A. El-Hafeez, Evaluation of left ventricular mass and function, lipid profile, and insulin resistance in Egyptian children with growth hormone deficiency: A single-center prospective case-control study, Indian journal of endocrinology and metabolism 17 (2013) 876-882.

42. R.T. Hamza, A.I. Hamed, M.T. Sallam, Effect of zinc supplementation on growth Hormone Insulin growth factor axis in short Egyptian children with zinc deficiency, Italian journal of pediatrics 38 (2012) 1-7.

43. T. Edouard, S. Grünenwald, I. Gennero, J.P. Salles, M. Tauber, Prevalence of IGF-1 deficiency in prepubertal children with isolated short stature, European journal of endocrinology 161 (2009) 43-50

44. G.R. Veiga, H.S. Ferreira, A.L. Sawaya, J. Calado, T.M. Florencio, Dyslipidaemia and undernutrition in children from impoverished areas of Maceio, 
state of Alagoas, Brazil, International journal of environmental research and public health 7 (2010) 4139-4151.

45. R. Stawerska, E. Czkwianianc, J. Smyczynska, M. Hilczer, A. Lewinski, Nutritional status in short stature children is related to both ghrelin and insulin-like growth factor I concentrations, Journal of pediatric gastroenterology and nutrition 64 (2017) 812-817.

46. M.D. DeBoer, R.J. Scharf, A.M. Leite, et al., Systemic inflammation, growth factors, and linear growth in the setting of infection and malnutrition, Nutrition 33 (2017) 248-253.

47. D.J. Millward, Nutrition, infection and stunting: the roles of deficiencies of individual nutrients and foods, and of inflammation, as determinants of reduced linear growth of children, Nutrition research reviews 30 (2017) 50-72.

48. G. Gat-Yablonski, M. Phillip, Nutritionallyinduced catch-up growth, Nutrients 7 (2015) 517-551.

49. R. Pando, B. Shtaif, M. Phillip, G. Gat-Yablonski, A serum component mediates food restrictioninduced growth attenuation, Endocrinology 155 (2014) 932-940.

50. C.P. Hawkes, A. Grimberg, Insulin-Like Growth Factor-I is a Marker for the Nutritional State, Pediatric endocrinology reviews 13 (2015) 499-511.

51. I.J. Griffin, Catch-up growth: Basic mechanisms, Nestle Nutrition Institute workshop series 81 (2015) 87-97.

52. L. Lin, J.H. Lee, E.D. Buras, et al., Ghrelin receptor regulates adipose tissue inflammation in aging, Aging 8 (2016) 178-191.

53. J.F. Alves, R.P. Britto, H.S. Ferreira, A.L. Sawaya, T.M. Florêncio, Evolution of the biochemical profile of children treated or undergoing treatment for moderate or severe stunting: consequences of metabolic programming?, Jornal de pediatria 90 (2014) 356-362.

54. M.O. Camurdan, A. Bideci, F. Demirel, P. Cinaz, Serum ghrelin, IGF-1 and IGFBP-3 levels in children with normal variant short stature, Endocrine journal 53 (2006) 479-484.

55. P. Wang, B. Ji, Q. Shao, M. Zhang, B. Ban, Association between Insulin-Like Growth Factor-1 and Uric Acid in Chinese Children and Adolescents with Idiopathic Short Stature: A Cross-Sectional Study, BioMed research international (2018) 1-6.

56. K. Takaya, H. Ariyasu, N. Kanamoto, et al., Ghrelin strongly stimulates growth hormone release in humans, The Journal of clinical endocrinology and metabolism 85 (2000) 4908-4911.

57. K. Howick, B.T. Griffin, J.F. Cryan, H. Schellekens, From belly to brain: Targeting the ghrelin receptor in appetite and food intake regulation, International journal of molecular sciences 18 (2017) 273-284.

58. M. Kojima, K. Kangawa, Ghrelin: structure and function, Physiological reviews 85 (2005) 495-522.

59. T.A. Sen, D.G. Simsek, S. Darcan, M. Coker, Ghrelin levels in children with constitutional delay of growth and puberty, Journal of clinical research in pediatric endocrinology 2 (2010) 117-121.

60. J.E. Pinsker, D. Ondrasik, D. Chan, et al., Total and acylated ghrelin levels in children with poor growth, Pediatric research 69 (2011) 517-521.

61. M. Razzaghy-Azar, M. Latifi, D. Ilbeygi, B. Larijani, M. Nourbakhsh, Total and acylated ghrelin levels in children and adolescents with idiopathic short stature and poor appetite, Acta Endocrinologica (Buc) 11 (2015) 401-406.

62. G. Erdemir, T.B. Ozkan, T. Ozgur, D. Altay, S. Cavun, G. Goral, Helicobacter pylori Infection in Children: Nutritional Status and Associations with Serum Leptin, Ghrelin, and IGF-1 Levels, Helicobacter 21 (2016) 317-324.

63. M. Kojima, K. Kangawa, Drug insight: the functions of ghrelin and its potential as a multitherapeutic hormone, Nature Reviews Endocrinology 2 (2006) 80-88.

64. C. De Vriese, J. Perret, C. Delporte, Current and future clinical applications of ghrelin, Endocrine Disease, IConcept Press Ltd2013, (2013) pp. 65-102.

65. P.A. Martins, A.L. Sawaya, Evidence for impaired insulin production and higher sensitivity in stunted children living in slums, The British journal of nutrition 95 (2006) 996-1001.

66. N.K. Francis, H.S. Pawar, A. Mitra, A. Mitra, Assessment of insulin sensitivity and its convalescence with dietary rehabilitation in undernourished rural west Bengal population, Journal of clinical and diagnostic research 11 (2017) 29-32.

67. A.P.G. Clemente, C.D.d.L. Santos, V.J. Martins, M.P. Albuquerque, M.B. Fachim, A.L. Sawaya, Lower waist circumference in mildly-stunted adolescents is associated with elevated insulin concentration, Jornal de pediatria 90 (2014) 479-485.

68. S.A. Khairy, M.K. Mattar, L.A. Refaat, S.S. ElSherbeny, Plasma micronutrient levels of stunted Egyptian school age children, Kasr El Aini Medical 
Journal 16 (2010) 1-6.

69. S.A. Ibrahim, A.M. Abd el-Maksoud, M.F. Nassar, Nutritional stunting in Egypt: which nutrient is responsible?, Eastern Mediterranean health journal 8 (2002) 272-280.

70. J.H. Yan, W.J. Wang, X.M. Luxo, et al., The Effect of Calcium and Zinc Preparation on Visual Development and the Level of Peripheral Blood Calcium, Zinc, and Lead in Stunting Children, Clinical Misdiagnosis and Mistherapy 5 (2011) 47-52.

71. M.S. Ejaz, N. Latif, Stunting and micronutrient deficiencies in malnourished children, The journal of the Pakistan medical association 60 (2010) 543547.

72. L. Lieben, B. Benn, D. Ajibade, et al., Trpv6 mediates intestinal calcium absorption during calcium restriction and contributes to bone homeostasis, Bone 47 (2010) 301-308.

73. A.M. Uwitonze, M.S. Razzaque, Role of magnesium in vitamin $\mathrm{D}$ activation and function, $\mathrm{J}$ Am Osteopath Assoc 118 (2018) 181-189.

74. R. Swaminathan, Magnesium metabolism and its disorders, The clinical biochemist reviews 24 (2003) 47-66.

75. Y. Zhang, Q. Li, Y. Xin, W. Lv, C. Ge, Association between serum magnesium and common complications of diabetes mellitus, Technology and Health Care (2018) 1-9.
76. M. Barbagallo, L.J. Dominguez, A. Galioto, et al., Role of magnesium in insulin action, diabetes and cardio-metabolic syndrome X, Molecular aspects of medicine 24 (2003) 39-52.

77. S. Ramadass, S. Basu, A. Srinivasan, Serum magnesium levels as an indicator of status of diabetes mellitus type 2, Diabetes and Metabolic Syndrome: Clinical Research and Reviews 9 (2015) 42-45.

78. S. Bo, E. Bertino, A. Trapani, et al., Magnesium intake, glucose and insulin serum levels in preschool very-low-birth weight pre-term children, Nutrition, metabolism and cardiovascular diseases 17 (2007) 741-747.

79. D. Shahbah, A.A. El Naga, T. Hassan, et al., Status of serum magnesium in Egyptian children with type 1 diabetes and its correlation to glycemic control and lipid profile, Medicine 95 (2016) e5166.

80. G.S. Aly, A.H. Shaalan, M.K. Mattar, H.H. Ahmed, M.E. Zaki, H.R. Abdallah, Oxidative stress status in nutritionally stunted children, Egyptian pediatric association gazette 62 (2014) 28-33.

81. E. Marasinghe, S. Chackrewarthy, C. Abeysena, S. Rajindrajith, Micronutrient status and its relationship with nutritional status in preschool children in urban Sri Lanka, Asia Pacific journal of clinical nutrition 24 (2015) 144-151. 